\title{
STUDENT FACILITATOR AND EXPLAINING UNTUK PEMBELAJARAN TIK BAHASA INDONESIA
}

\author{
Khusnul Khotimah, Leli Triana \\ Universitas Pancasakti Tegal \\ khusnulkups@gmail.com
}

Pertama diterima : 7 Juni 2021

Bukti akhir diterima : 30 Juni 2020

\begin{abstract}
Abstrak
Untuk mengetahui evektivitas penggunaan model pembelajaran Student Facilitator and Explaining atau SFE dalam keterampilan berfikir kritis dan mengetahui perbandingan antara kelompok yang menggunakan model pembelajaran dengan kelompok konvensional mahasiswa semester II Prodi Bahasa dan Sastra Indonesia 2021/2022. Kelompok yang menggunakan model Student Facilitator and Explaining atau SFE adalah kelompok eksperimen dan yang tidak menggunakan model adalah kelompok kontrol. Penelitian ini juga akan menganalisa bagaimanakah keefektifan model Student Facilitator and Explaining atau SFE, pada perkuliahan TIK mahasiswa semester II Prodi Bahasa dan Sastra Indonesia 2021/2022.

Populasi yang ada dan kemudian dianalisa yaitu seluruh mahasiswa semester II Prodi Bahasa dan Sastra Indonesia 2021/2022 dengan jumlah 3 kelas dengan total keseluruhan yaitu 75 mahasiswa, kemudian untuk mempersempit populasi maka diambil sampel sebanyak 50 mahasiswa yang terbagi dalam dua kelompok penelitian, kelompok A dengan jumlah 25 bertindak sebagai kelompok eksperimen sedangkan kelompok B berjumlah 25 bertindak sebagai kelompok kontrol. Teknik pengambilan sampel dalam penelitian ini mengadopsi teknik cluster random sampling. Sedangkan untuk Teknik pengumpulan data dalam penelitian ini menggunakan tes untuk melihat nilai. Kemudian dianalisis menggunakan uji t-non independent dan uji t independent.

Untuk simpulan hasil penelitian menunjukkan adanya peningkatan keterampilan berfikir kritis mahasiswa semester II Prodi Bahasa dan Sastra Indonesia 2021/2022 dengan menggunakan model pembelajaran Student Facilitator and Explaining atau SFE dengan hasil t hitung 7,51 > t tabel 1, 67 dari hasil perhitungan dengan uji t-non independent. Pembelajaran TIK menggunakan model pembelajaran Student Facilitator and Explaining atau SFE terbukti lebih efektif apabila dibandingkan dengan kelompok yang tidak menggunakan model pembelajaran dalam kegiatan perkuliahannya. Dibuktikan dari perhitungan kelompok eksperimen yaitu 83,60 terbilang besar dibandingkan dari kelompok kontrol yaitu 77,60. Dengan demikian diharapkan untuk setiap proses pembelajaran yang dilakukan hendaknya dimaksimalkan untuk menggunakan model pembelajaran agar mahasiswa memliki motivasi dalam belajar serta mampu meningkatkan hasil belajar atau nilai.

Kata Kunci : Model, Berpikir Kritis, TIK
\end{abstract}

\section{PENDAHULUAN}

Proses terwujudnya keberhasilan suatu kegiatan dapat dilihat dari perencanaan yang dibuat dengan matang. Segala kesiapan baik secara fisik maupun nonfisik tersedia dengan baik dan aplikatif akan sangat mendukung keberhasilan kegiatan tersebut. Hal ini berlaku dalam proses kegiatan belajar. Kegiatan belajar mengajar adalah sebuah proses terjadinya interaksi timbal balik yang positif untuk memahami informasi atau hal baru yang dimana proses tersebut dapat berjalan dengan efektif. Kesiapan sebelum pelaksanan kegiatan belajar, mengajar menjadi poin penting dalam tercapainya tujuan pembelajaran yang diinginkan. Hal tersebut merupakan tugas dan peran guru atau pendidik adalah sebagi jembatan untuk menuju jalan keberhasilan setiap anak didiknya. Selain itu fungsi guru adalah sebagai media yang dimana keberadaan seorang pendidik selalu dipandang mampu mentransfer ilmu yang dibutuhkan siswanya. Maka dari urgensi dari seorang pendidik hendaklah kegiatan belajar mengajar dipersiapakan sebaik mungkin.

Agar mahasiswa mampu menunjukkan kompetensinya dalam pembelajaran di mata kuliah TIK salah satunya dengan keaktifan selama proses belajar mengajar serta mampu memahami dengan baik dan berfikir secara kritis terhadap isu-isu baru yang ada di masyarakat. Sardiman (1996:45) mengemukakan bahwa, berfikir merupakan aktivitas mental untuk dapat merumuskan pengertian, mensistesis dan menarik kesimpulan. Sedangkan hal yang serupa dikemukakan oleh Santrock (2011:359) pemikiran kritis adalah pemikiran reflektif dan produktif, serta melibatkan evaluasi bukti.

Mata kuliah Teknologi informasi dan Komputerisasi (TIK) merupakan mata kuliah wajib bagi mahasiswa Prodi Pendidikan Bahasa dan Sastra Indonesia. Mengingat kemajuan teknologi yang selalu berkembang maka penguasaan teknologi pendidikan harus selalu diperbarui sesuai dengan kebutuhan khususnya di dalam pendidikan. Mahasiswa saat ini mereka masuk kedalam kategori generasi $\mathrm{Z}$, yaitu generasi yang lahir setelah internet 
ditemukan. Pada dasarnya mereka sudah sangat familiar dengan teknologi informasi akan tetapi terkait dengan TIK Pendidikan mereka masih sangat kurang dalam memahami dan mengaplikasikannya dalam proses pembelajaran.

Berdasarkan dari observasi dan temuan yang ada dilapangan proses pembelajaran TIK di Universiatas Pancasakti Tegal khususunya pada Prodi Pendidikan Bahasa Indonesia Universitas Pancasakti Tegal masih sangat kurang, terbukti dengan masih terpusatnya dosen dalam pembelajaran dan cara berfikir yang masih sangat hati-hati dan sederhana. Dan dibuktikan pula dengan hasil belajar pada tugas harian yang diberikan belum maksimal (relatif rendah).

Berpijak dari permasalahan yang ada, pembelajaran inovatif sangat diperlukan guna meningkatkan motivasi dan hasil belajar dalam mata kuliah TIK. Penerapan model pembelajaran Student Facilitator and Explaining atau SFE diduga cocok jika diterapkan dalam pembelajaran TIK Bahasa Indonesia. Model pembelajaran Student Facilitator and Explaining atau SFE merupakan model pembelajaran yang menekankan kegiatan siswa untuk mempresentasikan ide/pendapat pada rekan peserta laiinnya (Aqib, 2014:28). Diharapkan dengan penerapan model ini kegiatan pembelajaran TIK pada Prodi PBSI UPS Tegal pembelajaran akan berpusat pada mahasiswa dan kegiatan yang dilakukkan lebih bersifat kritis seperti, mahasiswa akan dilatih dalam mengemukakan pendapat, berdiskusi dan mahasiswa juga diharapkan mampu menjadi fasilitator untuk mahasiswa laiinya, sedangkan pendidik hanya memfasilitasi dan memotivasi mahasiswa agar pembelajaran tetap kondusif sehingga tujuan pembelajaran dapat terwujud. Saat mahasiswa belajar berperan sebagai fasilitator maka mahasiswa akan termotivasi dan pemahaman materi meningkat begitupula dengan hasil belajarnya.

Dari permasalahan tersebut di atas, peneliti menawarkan alternatif solusi dalam perbaikan proses pembelajaran, khususnya pada materi pengetahuan umum mengenai teknologi informasi dan penggunaan TIK dalam pembelajaran Bahasa Indonesia pada Prodi PBSI UPS Tegal dengan menerapkan model pembelajaran Student Facilitator and Explaining atau SFE agar kompetensi dan keterampilan mahasiswa tercapai sesuai dengan kriteria yang ditentukan.

\section{Landasan Teori}

Shoimin (2014) dalam pendapatnya tentang SFE mengungkapkan bahwa model pembelajaran ini mampu meningkatkan pemahaman peserta didik dalam menerima materi dengan seksama, karena model ini menuntut peserta didik untuk saling bekerjasama agar tujuan pembelajaran tercapai.

Sependapat dengan argument Huda (2014) bahwa model pembelajaran Student Facilitator and Explaining atau SFE adalah rangkaian seluruh pelaksaaan pembelajaran yang dimulai dari pendahuluan atau penyampaian materi, kemudian peserta didik diharapkan pula mampu memberikan atau menyampikan materi tersebut kepada temannya, kemudian pengajar dan peserta didik menyimpulkan hasil dari pendapat seluruh siswa yang terlibat dalam pembelajaran tersebut.

Berdasarkan dua pendapat di atas dapat disintesiskan yaitu Student Facilitator and Explaining atau SFE adalah model pembelajaran yang merangsang kemampuan dan potensi peserta didik untuk mampu mengimplementasikan pikirannya kepada teman-teman dalam pembelajaran.

Kemudian untuk pelaksanaan kegiatan pembelajaran dengan model SFE ada Langkah-langkah yang harus dilakukan.

a. Pengajar menyampiakan tujuan dan kompetensi apa yang hendak dicapai oleh peserta didik

b. Pengajar mendemonstrasikan materi

c. Pengajar memberikan ruang kepada peserta didik untuk menyampaikan materi kepada peserta didik yang lainnya

d. Pengajar menrefleksikan dari hasil kerja peserta didik

e. Pengajar menjelaskan materi yang lengkap terkait pembelajaran saat itu

f. Penutup

Berfikir kritis memiliki peran penting dalam proses pendewasaan seseorang untuk menentukan pilihan atau menyikapi suatu permasalahan. Dalam hal ini mahasiswa yang notabene adalah orang dewasa maka cara berfikir kritis harus benar-benar diarahkan sesuai dengan mekanisme yang baik.

Achmad (2013) menyampaikan pendapat terkait dengan berfikir kritis yaitu berfikir kritis adalah kemampuan esensial seseorang untuk mengaplikasikan nilai-nila dalam kehidupan bermasyarakat. Berfikir kritis juga memberikan kita kesempatan untuk selalu peka terhadap situasi dan Langkah terbaik yang akan kita lakukan dalam segala hal.

\section{METODE PENELITIAN}

Pendekatan dan jenis peneitian ini yaitu kuantitatif dan untuk jenisnya yaitu eksperimen. Penelitian eksperimen merupakan penelitian yang bertujuan untuk mengetahui apakah ada perbedaan antara objek yang 
diberikan treatment dan yang tidak diberikan treatment berdasarkan dari perhitungan kuantitatifnya. Campbell \& Stanley (dalam Arikunto, 2014:123) membagi jenis desain penelitian berdasarkan atas baik atau buruknya eksperimen, yaitu dengan Pre Experimental Desigen and True Experimental Desigen. Pelaksanaan penelitian nantinya dalam pembelajaran TIK pada kelompok eksperiman akan menggunakan Model Pembelajaran SFE sedangkan untuk kelompok kontrol perkuliahan materi TIK dilakukan tanpa menggunakan Model Pembelajaran SFE. Penelitian yang dilakukan juga akan mendeskripsikan model pembelajaran SFE apakah efektif dalam meningkatkan keterampilan berfikir kritis pada pembelajaran TIK Bahasa Indonesia. Berikut gambar metode penelitian yang akan dilakukan.

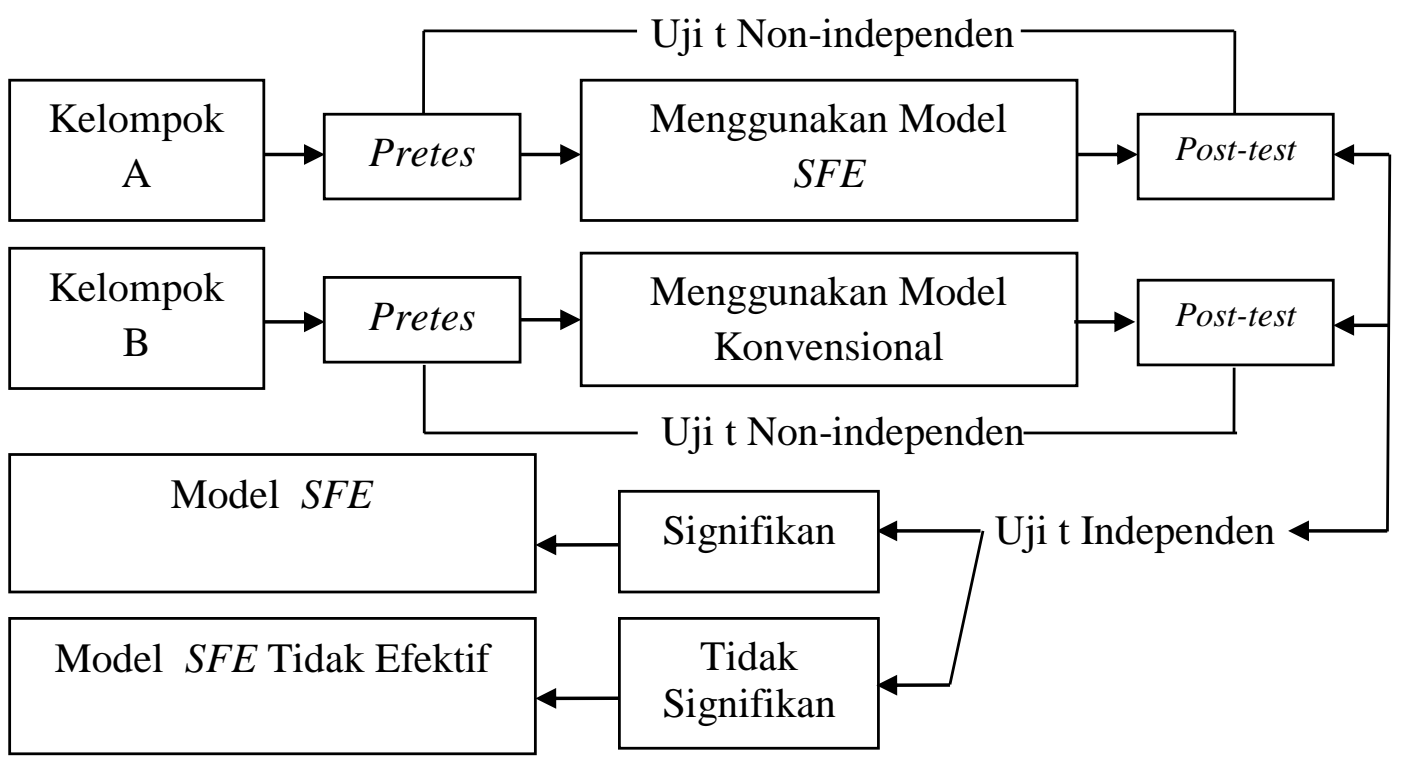

Gambar 1. Metode Penelitian

Variabel dalam penelitian ini adalah: a) variabel bebas yaitu Model Pembelajaran Student Facilitator and Explaining atau SFE,; b) variabel terikat atau (Y) yaitu keterampilan berfikir kritis.

Kegiatan penelitian ini mengambil populasi yaitu sejumlah mahasiswa semester II Prodi PBSI 2021/2022 yang mencakup dari jumlah 3 kelas dengan jumlah keseluruhan 75 mahasiswa, kemudian untuk sampel penelitian yang diambil yaitu sebanyak 50 mahasiswa yang dibagi menjadi dua kelompok penelitian. Kelompok A bertindak sebagai kelas eksperiman dengan jumlah mahasiswa 25 , dan untuk kelompok B bertindak sebagi kelas kontrol yang berjumlah 25 mahasiswa.

\section{Teknik Analisis Data}

Untuk mengetahui efektivitas penggunaan model pembelajarn $S F E$, dilakukan pengujian untuk mendapatkan hasil, Adapun rumus yang digunakan sebagai berikut.

\section{uji t-non independen}

$$
t=\frac{\bar{D}}{\sqrt{\frac{D^{2}-\frac{\left(\sum D\right)^{2}}{N}}{N(N-1)}}}
$$

Keterangan:

$\bar{D}=$ Selisih nilai $/$ skor post test dan pre test

$0,05=$ taraf signifikan $(\mathrm{TS})$

$D=$ Rata-rata selisih skor pretest dan postest

$\mathrm{N}-1=$ Derajat kebebasan

$\mathrm{N}=$ Jumlah sampel

Setelah mencari efektivitas penggunaan metode, selanjutnya dilakukan pengujian perbedaan dengan rumus berikut.

uji $t$ independen 


$$
\mathrm{t}=\frac{\overline{\mathrm{x}}_{1}-\overline{\mathrm{x}}_{2}}{\sqrt{\left(\frac{\sum x_{1}^{2}-\sum x_{2}^{2}}{n_{1}+n_{2}-2}\right)\left(\frac{1}{n_{1}}+\frac{1}{n_{2}}\right)}}
$$

Keterangan :

$\overline{\mathrm{X}_{1}}=$ Rata-rata nilai kelompok eksperimen

$\mathrm{x}_{1}=\mathrm{X}_{1}-\overline{\mathrm{X}_{1}}$ (kelompok eksperimen)

$\mathrm{n}_{1}=$ Jumlah sampel kelompok eksperimen

$\mathrm{dk}($ derajat kebebasan $)=n_{1}+n_{2}-2$
$\overline{\mathrm{X}_{2}}=$ Rata-rata nilai kelompok kontrol

$\mathrm{x}_{2}=\mathrm{X}_{2}-\overline{\mathrm{X}_{2}}$ (kelas kontrol)

$\mathrm{n}_{2}=$ Jumlah sampel kelompok kontrol

ts $($ taraf signifikan $)=0,05 ; 0,01$

Setelah menentukan rasio $t$, langkah selanjutnya yaitu mencari perbandingan dari hasil rasio t tersebut dengan nilai t tabel dan taraf signifikansinya 0,05 . Jika perhitungan hasil perbandingan menunjukan $t$ hitung lebih tinggi dari $\mathrm{t}$ tabel maka $\mathrm{H}_{\mathrm{o}}$ ditolak dan $\mathrm{H}_{1}$ diterima. Namun jika hasil perbandingan menunjukan $\mathrm{t}$ hitung lebih rendah dari $\mathrm{t}$ tabel maka $\mathrm{H}_{\mathrm{o}}$ diterima dan $\mathrm{H}_{1}$ ditolak.

\section{HASIL PENELITIAN DAN PEMBAHASAN}

Tahap akhir dari penelitian yaitu memaparkan hasil dan pembahasan,dalam bab ini akan dibahas tentang hasil tes keterampilan berfikir kritis mahasiswa semester II Prodi PBSI 2021/2022 yang terdiri dari 3 kelas dengan jumlah keseluruhan 75 mahasiswa, kemudian untuk sampel penelitian yang diambil yaitu sebanyak 50 mahasiswa yang dibagi menjadi dua kelompok penelitian. Kelompok A bertindak sebagai kelompok eksperiman dengan jumlah mahasiswa 25 , dan untuk kelompok B bertindak sebagi kelompok kontrol yang berjumlah 25 mahasiswa.

Untuk mendapatkan hasil yang maksimal maka dilakukan tes dua (2) kali pada masing-masing kelompok, tes tersebut berupa pretest dan postest. Berdasarkan langkah yang telah disusun pertemuan pertama pada kelompok kontrol maupun eksperimen kedua kelompok diberikan pemahaman dan materi ajar tentang keterampilan berfikir kritis tanpa diberikan model pembelajaran.

Kemudian kegiatan pembelajaran kedua mata kuliah TIK, peneliti merefleksikan pemahaman mahasiswa terkait keterampilan berfikir kritis yang sebelumnya telah diberikan materi tersebut lalu dilakukan tes untuk mendapatkan hasil nilai dari instrument keterampilan berfikir kritis yang telah disiapkan. Dari hasil tes yang diperoleh terdapat niali yang bervariatif sesuai dengan kemampuan mahasiswa dalam menjawab.

\section{Hasil Perolehan (Eksperimen)}

Hasil yang diperoleh pada kelompok eksperimen sebanyak dua kali didapatkan frekuensi skor pretest dan postest pada table dan diagram dibawah ini.

Tabel 2. Frekuensi skor pretest dan postest kelompok eksperimen

\begin{tabular}{|c|c|c|c|}
\hline \multicolumn{2}{|c|}{ Pretest } & \multicolumn{2}{c|}{ Postest } \\
\hline $\boldsymbol{1}$ & $\mathbf{2}$ & $\mathbf{3}$ & $\mathbf{4}$ \\
\hline Skor & Jumlah & Skor & Jumlah \\
\hline $41-50$ & 0 & $41-50$ & 0 \\
\hline $51-60$ & 1 & $51-60$ & 0 \\
\hline $61-70$ & 4 & $61-70$ & 0 \\
\hline $71-80$ & 20 & $71-80$ & 8 \\
\hline $81-90$ & 0 & $81-90$ & 17 \\
\hline $91-100$ & 0 & $91-100$ & 0 \\
\hline
\end{tabular}




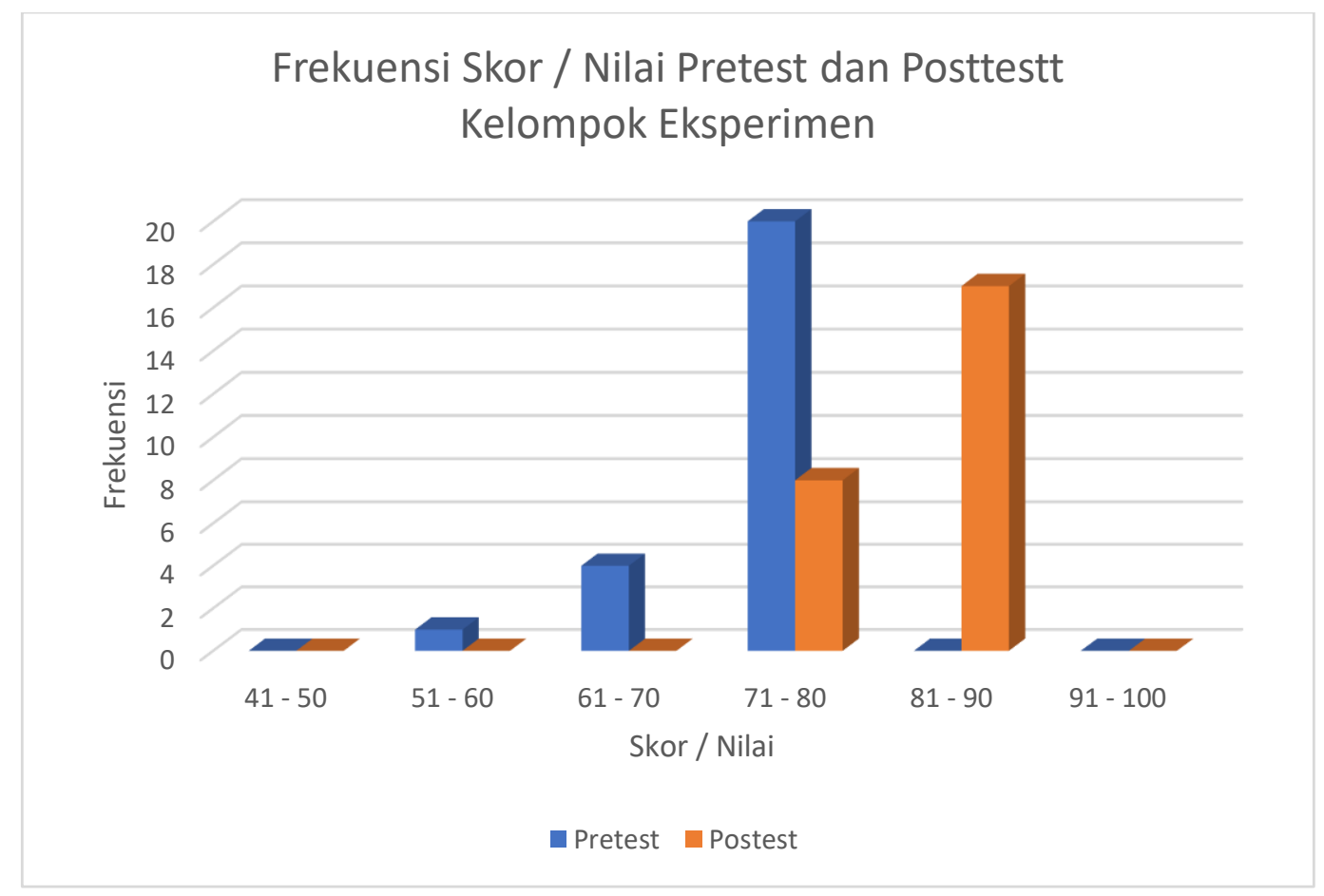

Gambar 2. Diagram Frekuensi kelompok eksperimen

Hasil yang diperoleh dalam olah data terdapat selisih jumlah antara pretest dan postest yaitu 180 kemudian setelah dikuadratkan maka diperoleh hasil yaitu 1850. Untuk perolehan nilai / skor rata-rata kelompok eksperimen yaitu 76,40 (pretest), sedangkan nilai / skor rata-rata hasil postest yaitu 83,60. Jumlah keseluruhan mahasiswa yang memperoleh skor / nilai minimal yang tidak memenuhi KKM 60 yaitu 1 mahasiswa untuk hasil pretest dan skor / nilai minimal 80 yaitu 8 mahasiswa untuk hasil postest. Dan untuk perolehan nilai tertinggi 80 ada 20 mahasiswa (pretest) dan skor / nilai 90 hanya ada 1 mahasiswa (postest). Hasil t hitung = 7,51 > t tabel df=1,68 yang berarti kegiatan pembelajaran TIK menggunakan Model Pembelajaran Student Facilitator and Explaining atau SFE memiliki dampak yang positif terhadap berfikir kritis mahasiswa. Berikut adalah data kelompok eksperimen dari hasil test yang dilakukan.

Tabel 3. Analisis Data Kelompok Eksperimen

\begin{tabular}{|c|c|c|c|c|}
\hline DATA NO & PRE TEST & POST TEST & $\mathrm{D}$ & $\mathrm{D}^{2}$ \\
\hline 1 & 75 & 85 & 10 & 100 \\
\hline 2 & 75 & 80 & 5 & 25 \\
\hline 3 & 80 & 85 & 5 & 25 \\
\hline 4 & 80 & 85 & 5 & 25 \\
\hline 5 & 75 & 80 & 5 & 25 \\
\hline 6 & 80 & 85 & 5 & 25 \\
\hline 7 & 80 & 85 & 5 & 25 \\
\hline 8 & 80 & 85 & 5 & 25 \\
\hline 9 & 80 & 90 & 10 & 100 \\
\hline 10 & 80 & 85 & 5 & 25 \\
\hline 11 & 70 & 80 & 10 & 100 \\
\hline 12 & 80 & 85 & 5 & 25 \\
\hline 13 & 65 & 80 & 15 & 225 \\
\hline 14 & 75 & 80 & 5 & 25 \\
\hline 15 & 80 & 80 & 0 & 0 \\
\hline 16 & 80 & 85 & 5 & 25 \\
\hline
\end{tabular}




\begin{tabular}{|c|c|c|c|c|}
\hline 17 & 80 & 85 & 5 & 25 \\
\hline 18 & 80 & 85 & 5 & 25 \\
\hline 19 & 80 & 85 & 5 & 25 \\
\hline 20 & 70 & 80 & 10 & 100 \\
\hline 21 & 80 & 85 & 5 & 25 \\
\hline 22 & 60 & 85 & 25 & 625 \\
\hline 23 & 80 & 85 & 5 & 25 \\
\hline 24 & 75 & 85 & 10 & 100 \\
\hline 25 & 70 & 80 & 10 & 100 \\
\hline JUMLAH & 1910 & 2090 & 180 & 1850 \\
\hline RATA-RATA & 76.40 & 83.60 & 7.20 & 74.00 \\
\hline
\end{tabular}

\section{Hasil Perolehan Data dari Kelompok Kontrol}

Setelah dilakukan test pada kelompok kontrol sebanyak dua kali diperoleh frekuensi skor pretest dan postest pada kelompok kontrol yaitu pada tabel dibawah ini.

Tabel 4. Frekuensi skor / nilai pretest dan postest pada kelompok kontrol

\begin{tabular}{|c|c|c|c|}
\hline \multicolumn{2}{|c|}{ Pretest } & \multicolumn{2}{c|}{ Postest } \\
\hline $\boldsymbol{1}$ & $\mathbf{2}$ & $\mathbf{3}$ & $\mathbf{4}$ \\
\hline Skor & Jumlah & Skor & Jumlah \\
\hline $41-50$ & 1 & $41-50$ & 0 \\
\hline $51-60$ & 9 & $51-60$ & 0 \\
\hline $61-70$ & 15 & $61-70$ & 1 \\
\hline $71-80$ & 0 & $71-80$ & 22 \\
\hline $81-90$ & 0 & $81-90$ & 2 \\
\hline $91-100$ & 0 & $91-100$ & 0 \\
\hline
\end{tabular}

\section{Frekuensi Nilai / Skor Pretest dan Posttestt Kelompok Kontrol}

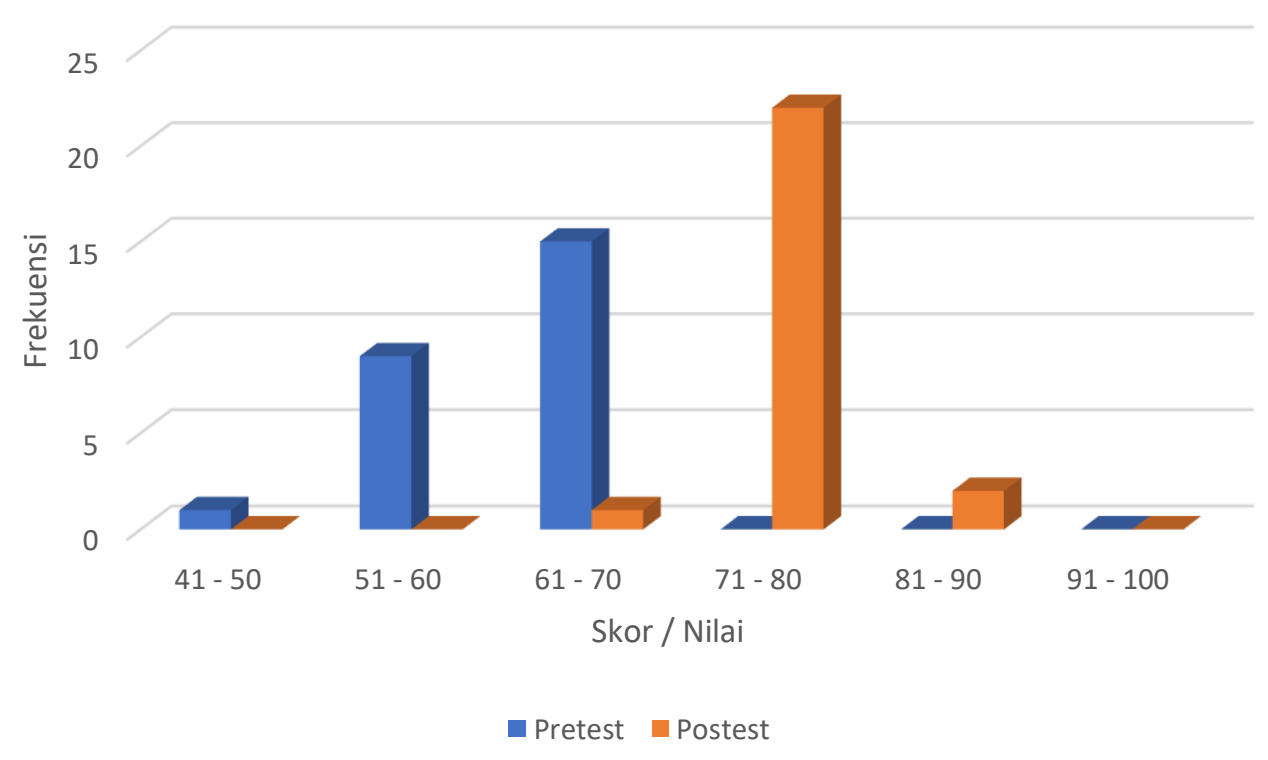

Gambar 3. Diagram Frekuensi Kelompok Kontrol 
Hasil yang diperoleh dalam olah data terdapat selisih jumlah antara pretest dan postest yaitu 370 kemudian setelah dikuadratkan maka diperoleh hasil yaitu 6400. Untuk perolehan rata-rata dari hasil pretest dan postest kelompok kontrol yaitu 62,80 untuk pretest dan 77,60 hasil untuk postest. Jumlah keseluruhan mahasiswa yang memperoleh nilai terendah yaitu 50 yaitu 1 mahasiswa (hasil pretest) sedangkan nilai terendah 70 yaitu 1 mahasiswa untuk postest. dan untuk nilai tertinggi 70 ada 8 mahasiswa (hasil pretest) dan 85 ada 2 mahasiswa (hasil postest). Untuk hasil $\mathrm{t}$ hitung $=14,17>\mathrm{t}$ tabel $\mathrm{d}_{\mathrm{f}}=1,68$. Dapat disimpulkan bahwa pelaksanaan perkuliahan TIK Model Pembelajaran Student Facilitator and Explaining atau SFE memiliki pengaruh positif pada keterampilan berfikir kritis mahasiswa. Berikut adalah data kelas kontrol dari hasil tes yang dilakukan.

Tabel 5. Analisis Data Kelompok Kontrol

\begin{tabular}{|c|c|c|c|c|}
\hline DATA NO & PRE TEST & POST TEST & $\mathrm{D}$ & $\mathrm{D}^{2}$ \\
\hline 1 & 50 & 70 & 20 & 400 \\
\hline 2 & 65 & 75 & 10 & 100 \\
\hline 3 & 55 & 75 & 20 & 400 \\
\hline 4 & 55 & 80 & 25 & 625 \\
\hline 5 & 60 & 80 & 20 & 400 \\
\hline 6 & 65 & 80 & 15 & 225 \\
\hline 7 & 65 & 75 & 10 & 100 \\
\hline 8 & 70 & 75 & 5 & 25 \\
\hline 9 & 55 & 75 & 20 & 400 \\
\hline 10 & 55 & 80 & 25 & 625 \\
\hline 11 & 55 & 80 & 25 & 625 \\
\hline 12 & 55 & 75 & 20 & 400 \\
\hline 13 & 55 & 75 & 20 & 400 \\
\hline 14 & 65 & 75 & 10 & 100 \\
\hline 15 & 65 & 75 & 10 & 100 \\
\hline 16 & 60 & 75 & 15 & 225 \\
\hline 17 & 65 & 80 & 15 & 225 \\
\hline 18 & 70 & 80 & 10 & 100 \\
\hline 19 & 70 & 80 & 10 & 100 \\
\hline 20 & 65 & 80 & 15 & 225 \\
\hline 21 & 70 & 75 & 5 & 25 \\
\hline 22 & 70 & 75 & 5 & 25 \\
\hline 23 & 70 & 80 & 10 & 100 \\
\hline 24 & 70 & 85 & 15 & 225 \\
\hline 25 & 70 & 85 & 15 & 225 \\
\hline JUMLAH & 1570 & 1940 & 370 & 6400 \\
\hline RATA-RATA & 62.80 & 77.60 & 14.80 & 256.00 \\
\hline
\end{tabular}

Berdasarkan hasil perhitungan uji t non independent pada dua kelompok yaitu kelompok kontrol dan kelompok eksperimen, hasil analisis perhitungan $t$ hitung $=98,11>t$ tabel 2,00 yang berarti hipotesis nihil (Ho) ditolak dan hipotesis kerja (Ha) diterima. Dengan demikian, diperoleh hasil yang signifikan sehingga dapat disimpulkan bahwa Model Pembelajaran Student Facilitator and Explaining atau SFE mempunyai pengaruh positif terhadap peningkatan berfikir kritis mahasiswa. Peneliti mendapatkan perbedaan ketrampilan berpikir kritis antara kelompok kontrol dan kelompok eksperimen yang diberi pengajaran menggunakan Model Pembelajaran Student Facilitator and Explaining atau SFE. Pada kelompok eksperimen yang menggunakan Model Pembelajaran Student Facilitator and Explaining atau SFE dalam pembelajaranya didapatkan hasil t hitungnya adalah 7,51. Sedangkan pada kelompok control yang tanpa menggunakan Model Pembelajaran Student Facilitator and Explaining atau SFE dalam pembelajaranya didapatkan hasil t hitungnya adalah 14,17. Dari hasil tersebut dapat disimpulkan bahwa hipotesis awal (Ho) ditolak dan hipotesis kerja (Ha) diterima. 


\section{Perbandingan antara penggunaan model pembelajaran dan konvensional}

\section{a. Kelompok yang menggunakan model pembelajaran}

Setelah dilakukan penelitian dan tes dengan instrument yang telah dipersiapkan maka diperoleh data yang menggambarkan pelaksanaan perkuliahan TIK pada mahasiswa semester II Prodi PBSI UPS Tegal.

1. Mahasiswa termotivasi untuk berfikir secara kritis dalam menyikapi permasalahan.

2. Mahasiswa belajar dengan bersungguh-sungguh karena mereka memiliki tanggungjawab untuk mengajarkan materi kepada temannya.

3. Kepercayaan diri meningkat dikarenakan mereka harus mampu membawakan materi dengan baik dan meyakinkan untuk temannya.

4. Ide-ide dan pemikiran baru akan terasah dan meningkat karena peserta didik dituntuk untuk aktif dalam bekerjaama dengan kelompok.

\section{b. Kelompok konvensional}

1. Mahasiswa kurang termotivasi dalam melaksanakan perkuliahan khusunya mata kuliah TIK, karena mata kuliah TIK lebih menekankan pada teori serta praktik yang kompleks.

2. Mahasiswa tidak memiliki tanggung jawab untuk menyampikan materi yang mereka dapatkan untuk disampaikan ke teman lainnya

3. Mahasiswa kurang aktif dalam mengikuti pembelajaran TIK, merasa bosan karena banyak hal-hal baru dalam materi tersebut.

4. Kurang memanfaatkan ide-ide dalam menjawab atau mengikuti perkuliahan TIK Bahasa Indonesia.

Dengan demikian dapat disimpulkan bahwa Model Pembelajaran Student Facilitator and Explaining atau SFE lebih efektif diterapkan dalam pembelajaran TIK (Teknologi Informasi dan Komputerisasi) dibandingkan dengan metode konvensional (tanpa model pembelajaran) sesuai dengan hasil dari uji $\mathrm{t}$ independent yaitu 98,11>t tabel 2,00. Berdasarkan perhitungan dan analisa kegiatan perkuliahan TIK yang menggunakan Model Pembelajaran Student Facilitator and Explaining atau SFE lebih efektif digunakan dalam mata kuliah TIK Bahasa Indonesia.

\section{SIMPULAN}

Model Pembelajaran Student Facilitator and Explaining atau SFE terbukti lebih efektif diaplikasikan dalam pembelajaran TIK dibandingkan dengan tidak menggunakan Model Pembelajaran Student Facilitator and Explaining atau SFE dalam pembelajaran TIK pada mahasiswa semester II Prodi Bahasa dan Sastra Indonesia 2021/2022. Dibuktikan dengan rata-rata nilai pada kelompok eksperimen 83,60 lebih besar dari kelas kontrol yang rata-ratanya hanya 77,60. Kegiatan perkuliahan khsusunya pembelajaran TIK menggunakan Model Pembelajaran Student Facilitator and Explaining atau SFE mahasiswa lebih aktif dan kreatif dalam menerima materi TIK, sebab mahasiswa bisa menuangkan ide mereka dengan baik dan terstruktur. Saran yang dapat diberikan untuk peneliti setelahnya yaitu, seyogyanya setiap pendidik atau pengajar harus memberikan fasilitas belajar yang maksimal sesuai dengan kebutuhan peserta didiknya.

\section{DAFTAR PUSTAKA}

Arief Achmad. 2013. Memahami Berpikir Kritis. http://researchengines.com/1007arief3.html Arikunto, Suharsimi. 2014. Prosedur Penelitian Suatu Pendekatan Praktik. Jakarta: Rineka Cipta.

Aqib, Zainal. 2014. Model-Model, Media, dan Strategi Pembelajaran Kontekstual (Inovatif). Bandung: Yrama Widya.

Ennis, Robert H. 1991. Critical Thinking. New Jersey: Printice-Hall Inc.

Huda, Miftahul. 2014. Model-Model Pengajaran Dan Pembelajaran:Isu Metodis dan Paradigmatik. Yogyakarta: Pustaka Pelajar.

Santrock, John W. 2011. Perkembangan Anak edisi 7 jilid 2. (terjemahan : Sarah Genis B) Jakarta: Erlangga.

Sardiman, M. 1996. Interaksi Dan Motivasi Belajar Mengajar. Jakarta: Rajawali Pers.

Shoimin, Aris. 2014. 68 Model Pembelajaran Inovatif Dalam Kurikulum 2013. Yogyakarta :Ar-ruzz Media.

Susilowati, Sajidan dan Murni Ramli. 2017. Pengembangan Modul Berbasis Iquiry Lesson Untuk Memberdayakan Keterampilan Berfikir Kritis Siswa Pada Materi Ekskresi Manusia. Thesis. Pascasarjaan Universitas Negeri Sebelas Maret Surakarta. File://CUsers/user-pc/Downloads/11417-23912-1-SM.pdf. 